\title{
Repercussões sociais no hábito alimentar dos obesos ${ }^{1}$
}

\section{Social repercussions on the food \\ habit of obese individuals}

\author{
Ricardo de Carvalho COSTA ${ }^{2}$ \\ Dimitri Carlo GABRIEL ${ }^{3}$ \\ Maria José de Carvalho COSTA ${ }^{4}$ \\ Maria da Conceição Rodrigues GONÇALVES ${ }^{4}$ \\ Sônia Cristina Pereira de OLIVEIRA \\ Luiza Sonia ASCIUTTI ${ }^{5}$
}

\section{Resumo}

O trabalho tem como objetivo analisar os fatores sociais do cotidiano que mais influenciam no hábito alimentar do obeso. A pesquisa, de enfoque qualitativo, teve como participantes 11 indivíduos obesos que frequentavam o ambulatório de nutrição de um hospital público na cidade de João Pessoa, Paraíba, Brasil. Foram realizadas entrevistas semiestruturadas, gravadas para a análise de conteúdo. Observou-se que as categorias que se destacaram nos discursos foram: autoimagem negativa, discriminação, ansiedade e sentimento de culpa. Ao se tornarem obesos, os indivíduos do presente estudo parecem desenvolver uma autoimagem negativa, relacionada à ansiedade e à depressão, entre outros fatores, o que pode levar a um sentimento de culpa, reforçado pela discriminação da sociedade que, ao invés de ajudá-lo a perder peso, parece estimulá-lo a comer mais.

Unitermos: Hábitos alimentares. Obesidade. Sociedade.

\begin{abstract}
The objective of this study was to analyze the social factors of the daily life that most influence the food habits of obese individuals, using a qualitative approach. Participants were 11 obese patients attended at the Nutrition Clinics of a public hospital in the city of João Pessoa, Paraíba, Brazil. Semi-structured and recorded interviews were held for content analysis. It was observed that the categories that stood out in the interviews were negative self-image, discrimination, anxiety and guilt feeling. When becoming obese, individuals create a negative self-image that causes anxiety and depression, among otherfactors, which may lead them to a guiltfeeling, reinforced by social discrimination that instead of helping them losing weight, seems to encourage them to eat more.
\end{abstract}

Uniterms: Food habits. Obesity. Society.

\section{$\boldsymbol{\nabla \nabla \nabla \nabla}$}

1 Artigo elaborado a partir da dissertação de R.C. COSTA, intitulada "A Interferência da sociedade no hábito alimentar dos obesos na concepção desses". Universidade Federal da Paraíba, 2006. Apoio: Coordenação de Aperfeiçoamento de Pessoal de Nível Superior.

2 Universidade Federal da Paraíba, Centro de Ciências da Saúde, Programa de Pós-Graduação em Ciências da Nutrição. João Pessoa, PB, Brasil.

3 Universidade Estadual do Piauí, Centro de Ciências da Saúde, Faculdade de Ciências Médicas, Departamento de Psicologia. Terezinha, PI, Brasil.

- Universidade Federal da Paraíba, Centro de Ciências da Saúde, Departamento de Nutrição. Cidade Universitária, Campus I, Castelo Branco I, João Pessoa, PB, Brasil. Correspondência para/Correspondence to: M.C.R. GONÇALVES. E-mail: <raulceica@ig.com.br>.

5 Universidade Federal da Paraíba, Centro de Ciências da Saúde, Faculdade de Ciências Médicas da Paraíba. João Pessoa, PB, Brasil. 
A obesidade é uma condição frequentemente descrita como aquela na qual existe um excesso de peso corpóreo, cerca de vinte e cinco a trinta por cento acima do peso ideal estimado. Sua prevalência vem crescendo acentuadamente nas últimas décadas, inclusive nos países em desenvolvimento, o que levou a doença à condição de epidemia global - epidemia do século XXI (Contaldo \& Pasanisi, 2004; Drewnowski \& Specter, 2004).

É uma patologia associada à hiperlipidemia e ao diabetes Mellitus tipo Il, duas condições intimamente relacionadas com doenças cardiovasculares, que afetam grande contingente da população, além de também ser associada a fatores psicológicos, tais como depressão e stress aumentado, entre outros (Savage \& Ades, 2006).

Resulta de uma complexa interação de variáveis biológicas, comportamentais, cognitivas, familiares, culturais e econômicas, que influenciam seu desenvolvimento e manutenção (Brownell, 2000; Faith, Flint, Fairburn, Godwin \& Alison, 2001). É uma condição que altera o aspecto físico do indivíduo, distanciando-o daquele considerado pela sociedade como padrão, ou seja, o indivíduo magro, esbelto etc. (Cardoso, 2000).

Além de abalar o aspecto emocional do indivíduo obeso por esse padrão, a sociedade facilita hábitos alimentares errôneos que favorecem o ganho de peso (difundidos pela televisão, filmes e propagandas) e ainda disponibiliza refeições rápidas (fastfood), sobremesas e lanches extremamente energéticos (Derrene \& Beresin, 2006; Hancox \& Poulton, 2006; Prentice \& Jebb, 2003).

De acordo com Cardoso (2000), o aspecto físico, mais do que as qualidades intrínsecas, assume uma posição de grande importância nos indivíduos, quer nas interações que eles estabelecem, quer nos processos de integração e aceitação social pelos quais passam. Logo, o aspecto físico atua como elemento de promoção, inclusão ou exclusão do sujeito no tecido social.

Segundo Scwartz e Brownell (2004), o descontentamento com a vida social, as responsabilidades e a aflição da imagem do corpo produzida pela obesidade, podem motivar o indivíduo a perder peso, mas é mais

510 provável que esses fatores formem barreiras na regula- ção da emoção, o que pode conduzir a um aumento na ingestão de alimentos.

A preocupação com o corpo tanto é estimulada como sabotada pelos meios de comunicação, que veiculam ou produzem notícias, representações e expectativas nos indivíduos, com propagandas ou informações que, de um lado estimulam o uso de produtos dietéticos e práticas alimentares para emagrecimento e, de outro, instigam o consumo de lanches e refeições rápidas. Os programas apresentados na televisão mostram constantemente escolhas de alimentos não saudáveis, tais como aqueles de alta densidade energética e bebidas alcoólicas, sem esclarecer sobre as sequelas que seu consumo cotidiano pode acarretar para a saúde (Almeida, Nascimento \& Bolzan, 2002; Volkow et al., 2002).

Muito embora na literatura existam inúmeros trabalhos sobre os aspectos fisiopatológicos da obesidade, são escassas as pesquisas envolvendo a interferência da sociedade no hábito alimentar dos obesos, com raros estudos direcionados ao entendimento mais amplo da questão. Nesse contexto, buscou-se analisar a interferência da sociedade no hábito alimentar dos obesos, na concepção destes, com o intuito de contribuir para a adoção de políticas de intervenção.

\section{Método}

\section{Desenho do estudo e casuística}

Foi utilizada a metodologia qualitativa de pesquisa, considerando que este trabalho buscou conhecer os sentidos e significações dadas ao conjunto de percepções, sentimentos e vivências da população estudada (Nogueira-Martins, 2004).

Esta pesquisa foi desenvolvida sob uma perspectiva fenomenológica existencial de cunho qualitativo. A opção por essa natureza de pesquisa baseia-se na preocupação com um nível de realidade de difícil quantificação, ou seja, a pesquisa qualitativa leva ao entendimento dos meandros das relações sociais e afetivas, trabalhando com o universo de significados, crenças e valores, compreendendo e explicando essa dinâmica.

O critério para a escolha da casuística baseou-se nas seguintes condições: que os indivíduos fossem 
obesos que frequentassem o ambulatório de nutrição de um determinado hospital público na cidade de João Pessoa, Paraíba, Brasil, fossem adultos na faixa etária de 18 a 60 anos (faixa considerada representativa de adultos no Brasil), e não estivessem em uso de medicação anorexígena.

Dentre os indivíduos recrutados, não houve recusa quanto à participação na pesquisa. Foram incluídos no estudo 11 obesos, voluntários, que frequentavam o ambulatório de nutrição de um hospital público da cidade de João Pessoa, no período compreendido entre dezembro de 2004 e junho de 2005. Antes de sua inclusão na amostra, os participantes foram informados sobre o estudo e esclarecidos sobre seus direitos, de acordo com a Resolução no 196/96 do Conselho Nacional de Saúde (1996), tendo assinado o respectivo Termo de Consentimento Livre e Esclarecido. A pesquisa foi aprovada pelo Comitê de Ética em Pesquisa com Humanos, do próprio hospital, sob Protocolo n 031/ 2000 .

\section{Instrumento}

Utilizou-se a entrevista semiestruturada, no sentido de haver uma pré-estrutura mínima que permitisse ao entrevistado espontaneidade e fluência de expressão. Tal forma de entrevista combina perguntas fechadas (ou estruturadas) e abertas, de modo que o entrevistado tem a possibilidade de discorrer sobre o tema proposto, sem respostas ou condições prefixadas pelo pesquisador. A escolha desse instrumento deu-se a partir do relato de Minayo (1999, p.58), segundo quem a entrevista semiestruturada permite captar a informação desejada, além de possibilitar ao entrevistado a liberdade e a espontaneidade para expressar-se sobre o tema. Através desse procedimento, podem obter-se dados objetivos e subjetivos acerca do assunto investigado.

As entrevistas duraram, em média, 30 minutos e foram realizadas em uma sala reservada, situada no mencionado hospital, em uma atitude clínica, conforme recomenda Turato (2003) para os casos de método qualitativo aplicado em setting de saúde.

Embora o instrumento tenha sido desenvolvido a partir de um esquema básico constituído por questões norteadoras (O que é obesidade para você? Na sua opinião como as pessoas tratam a pessoa obesa? O que é que te (faz) influencia a comer mais?), não foi aplicado rigidamente, permitindo ao entrevistador fazer as necessárias adaptações a partir dos dados fornecidos pelo entrevistado durante o curso da entrevista (Lüdke \& André, 1986).

Para a análise do material obtido nas entrevistas, foi utilizado o procedimento da análise temática, consistente em"descobrir os núcleos de sentido que compõem uma comunicação, cuja presença ou frequência signifiquem alguma coisa para o objetivo analítico visado" (Minayo, 1999, p.58).

\section{Tratamento e análise dos dados}

A coleta dos dados e a consequente análise dos conteúdos foram organizadas em etapas, tais como, pré-análise, exploração do material, tratamento dos resultados, inferência e interpretação.

Foi utilizada a análise de conteúdo que, de acordo com Bardin (2004, p.37), consiste em "um conjunto de técnicas de análise das comunicações, visando, por procedimentos sistemáticos e objetivos de descrição do conteúdo das mensagens, obterem indicadores quantitativos ou não, que permitam a inferência de conhecimentos relativos às condições de produção/ recepção (variáveis inferidas) das mensagens".

\section{Resultados}

Dos 11 entrevistados, nove eram do sexo feminino e dois do masculino, na faixa etária de 25 a 60 anos. A renda familiar média era de $\mathrm{R} \$ 760,00$, e apenas 2 cursavam o terceiro grau.

Os resultados estão descritos a partir das categorias encontradas nas entrevistas.

Ao se analisarem as entrevistas realizadas com os indivíduos obesos, as categorias que se destacaram nos discursos foram a autoimagem negativa (apresentada no relato de 3 entrevistados), discriminação (apresentada no relato de 8 entrevistados), ansiedade (apresentada no relato de 4 entrevistados) e o sentimento de culpa (apresentado no relato de 3 entrevistados).

Os Quadros 1 e 2 apresentam as verbalizações que se enquadraram nas devidas categorias. 
Quadro 1. Verbalizações das categorias autoimagem negativa e discriminação. João Pessoa (PB), 2006.

\begin{tabular}{|c|c|c|}
\hline Categoria & Indivíduo & Verbalizações \\
\hline \multirow[t]{3}{*}{ Autoimagem negativa } & 3 & $\begin{array}{l}\text { "Estou me sentindo muito pesada, não gosto de me olhar no espelho... minhas roupas não } \\
\text { cabem mais". }\end{array}$ \\
\hline & 4 & "Eu me sinto feia". \\
\hline & 6 & "Eu me olho no espelho, e me acho enorme... tenho vontade de chorar... eu me "aperreio"..." \\
\hline \multirow[t]{7}{*}{ Discriminação } & 1 & "Ficam sempre mexendo com você". \\
\hline & 2 & "Às vezes acho que discriminam". \\
\hline & 3 & $\begin{array}{l}\text { "... Tratam com discriminação, acham que a pessoa é preguiçosa, desleixada, que a gente } \\
\text { não se cuida". }\end{array}$ \\
\hline & 4 & "Me chamam de baleia...". \\
\hline & 7 & $\begin{array}{l}\text { "Tem sempre um preconceito, a princípio, todas elas são rotuladas de gorda, hei gordinho, } \\
\text { tudo mais..."'problema sempre acontece quando você vai ter relacionamento, fulaninho, } \\
\text { você é muito legal, você é muito carismático, inteligente, mas você é gordinho; então, isso } \\
\text { para todo gordo sempre é um impacto...". }\end{array}$ \\
\hline & 8 & "Tratam com preconceito, não é?...". \\
\hline & 11 & $\begin{array}{l}\text { "Meu marido dizia que me amava, que gostava de mim assim mesmo, ai me trocou por outra } \\
\text { mais nova e magrinha...". }\end{array}$ \\
\hline
\end{tabular}

Quadro 2. Verbalizações das categorias ansiedade e sentimento de culpa. João Pessoa (PB), 2006.

\begin{tabular}{|c|c|c|}
\hline Categoria & Indivíduo & Verbalizações \\
\hline \multirow[t]{4}{*}{ Ansiedade } & 5 & $\begin{array}{l}\text { "Sem nada, de repente... dá aquela ansiedade em mim, é uma coisa estranha, aí eu vou } \\
\text { procurar, às vezes até os "bobes" (cabelo) eu mudo, pra ver se eu esqueço da comida, até } \\
\text { fazer algum trabalho, mas, quando termino, fico sentindo uma falta...". }\end{array}$ \\
\hline & 6 & $\begin{array}{l}\text { (quando se olha no espelho) "Ave Maria! me sinto... Ave Maria! tenho uma vontade de chorar } \\
\text { eu me aperreio, ai meu Deus, aí pronto, aí se eu ficar mais assim, aí é que eu fico com vontade } \\
\text { de comer". }\end{array}$ \\
\hline & 8 & "Eu não gosto de ficar em casa, fico agoniada e começo a comer...". \\
\hline & 9 & "Me sinto angustiada...". \\
\hline \multirow[t]{3}{*}{ Sentimento de culpa } & 3 & $\begin{array}{l}\text { "Eu tento me controlar, mas às vezes eu não consigo, já até joguei comida para eu não } \\
\text { comer". }\end{array}$ \\
\hline & 5 & $\begin{array}{l}\text { "Eu não aguento ficar em casa sem comer... eu gosto de estudar... nas últimas semanas } \\
\text { engordei muito, eu não gosto mais nem de pensar... eu não acho justo com meu marido e } \\
\text { meus filhos estar com esse peso (chora)...". }\end{array}$ \\
\hline & 9 & $\begin{array}{l}\text { "... Às vezes eu saio com meu marido, assim, na semana, para comer pastel; tem nada a ver } \\
\text { comer pastel! tem nada a ver a pessoa com janta em casa comer pastel com suco e } \\
\text { refrigerante!...". }\end{array}$ \\
\hline
\end{tabular}

\section{Discussão}

512 não cabem mais". (Ind.4) - "Eu me sinto feia".
A autoimagem negativa faz-se presente no discurso dos entrevistados, como relatado a seguir:

Indivíduo3 (Ind.3) - "Estou me sentindo muito pesada, não gosto de me olhar no espelho... minhas roupas
(Ind.6) - "Eume olho no espelho eme acho enorme... tenho vontade de chorar... eu me "aperreio"..".

O ser humano, segundo Morato (1999), é o "ser aí" (Dasein) e este "ser aí" é sempre no mundo e sempre percebe e responde ao ser, portanto, tem seu ser mesmo como questão ou tarefa; tudo que vê, vê através de seu ser-no-mundo. Logo, essa autoimagem se configura no conceito de Dasein de Martin Heidegger. 
Para Rogers (1992), autoimagem é a ideia ou imagem de si mesmo, formada das percepções referentes ao próprio indivíduo em sua relação com os outros, com o ambiente e com a vida em geral. "Auto"e "imagem" são duas palavras distintas que, juntas, possuem grande força. "Auto" pode ser entendido como "por si", "próprio", enquanto "imagem" pode ser "figura", "aquilo que imita pessoa ou coisa"; logo, autoimagem (self) é uma simbolização que o indivíduo faz de si mesmo e assim como se lhe fosse própria. Ao mesmo tempo, a autoimagem também tem influências importantes advindas dos outros, da cultura e do mundo que rodeia o indivíduo.

Sabe-se que a imagem corporal pode ser considerada um retrato mental que um indivíduo faz de sua aparência física e da sua relação com seu corpo. O obeso muitas vezes possui uma imagem corporal distorcida, e essa distorção é mais presente e intensa quanto mais antiga for sua obesidade (Betarrello, 1998).

A cultura do aspecto físico do indivíduo passou por uma intensa variação; aquilo que, em séculos passados, era cultivado como belo, a corpulência, atualmente é associado ao feio, ao negativo; enquanto o belo passou a ser sinônimo de magreza, a corpulência ficou associada ao feio, ao negativo (Stenzel, 2000).

A supervalorização cultural da estética torna a obesidade uma doença ainda mais complexa, pois o indivíduo obeso sente-se fora dos padrões determinados pela cultura atual, chegando a sentir-se deformado, quando relata "me sinto enorme", "não gosto de me olhar no espelho", "me chamam de baleia", e discriminado, podendo isso causar-lhe desde tristeza até depressão. E, no caso das mulheres, o que é estar deformada, se há alguns séculos ser deformada era ser magra, e a beleza estética estava nas mulheres mais cheias. A questão estética, portanto, assume papel "escravizante" na sociedade, em qualquer época - e igualmente nos dias atuais, com a globalização, em que a "moda da cultura da magreza" e a "do corpo sarado" são "guia da felicidade", como máquina que move os desejos.

Fica evidenciado que a visão sobre os obesos sofreu modificações ao longo da história, e que hoje eles sofrem preconceito, discriminação e marginalização. No presente estudo, os indivíduos relataram o sentimento de se sentirem discriminados, da seguinte forma:
(Ind.3) -"...Tratam com discriminação, acham que a pessoa épreguiçosa, desleixada, que a gente não se cuida".

(Ind.4) - "Às vezes acho que discriminam".

(Ind.1) -"Ficam sempremexendo com você".

(Ind.8) - "Tratam com preconceito, não é?...."

A ridicularização, as humilhações, o rebaixamento e o desprezo constituem ameaças à autoimagem, na percepção que cada um tem de si mesmo.

Nas últimas décadas, o obeso, desde a infância, é o alvo preferido dos colegas de escola, das ruas, e carrega isto por toda a sua vida, sendo sempre motivo de risos e piadas maldosas, como é evidenciado nos discursos abaixo:

(Ind.1) - "Ficam sempre mexendo com você: hei gordo!".

(Ind.4) -"Mechamam de baleia...".

(Ind.7) - "Tem sempre um preconceito, a princípio, todas elas são rotuladas de gorda, hei gordinho, tudo mais...".

A partir dessas respostas, observa-se que o indivíduo obeso é tratado como uma pessoa preguiçosa, que não tem força de vontade ou coragem para perder peso.

Esses dados vão ao encontro do que relatam Schwartze Brownell (2004) sobre o descontentamento com vida social, as responsabilidades, e a aflição com a imagem do corpo produzida pela obesidade, podendo motivar a necessidade de perder peso. Ao contrário, conforme outros estudiosos, é mais provável que esses fatores formem barreiras na regulação da emoção, o que conduziria a um aumento na ingestão de alimentos. Esses fatores sociais são mais compreendidos como mensagens negativas sobre o ser "obeso", o que reflete uma forte polarização antiobeso, evidente nos meios de comunicação, em instituições como escolas e empresas, e também no discurso diário, resultando no estigma e na discriminação (Puhl \& Brownell, 2003). Ironicamente, é nesses ambientes que ocorrem os maiores estímulos para o aumento da prevalência dessa patologia, pois os indivíduos são aí expostos a propagandas de alimentos ricos em calorias e à disponibilidade de lanches hipercalóricos, constituindo essa realidade um paradoxo criado pela própria sociedade. 
Essa discriminação, como qualquer outra, segrega o indivíduo, dificultando os relacionamentos, as amizades, a vida social e a própria vida familiar, como ficou claro nas respostas dos pacientes participantes do presente estudo:

(Ind.7)-“... problema sempreacontecequando você vaiter relacionamento, fulaninho, vocêémuito legal, você é muito carismático, inteligente, mas você é gordinho; então, isso para todo gordo sempreé um impacto..." .

(Ind.11) - "Meu marido dizia que me amava, que gostava de mim assim mesmo, aíme trocou poroutra, mais nova e magrinha...".

Todos esses aspectos parecem acentuar um estado de ansiedade/angústia, que também foi evidenciado nos depoimentos e constituem uma outra categoria que foi verificada.

O estado de angústia/ansiedade, para a psicologia, reflete o momento em que o indivíduo estreita seu ser, tentando caber em espaços emocionais que lhe são impostos e nos quais ele não consegue se expandir. A presença de um permanente estado de angústia/ansiedade é um fator que provavelmente irá conduzir o indivíduo obeso à maior ingestão de alimentos, comportamento que parece ser o único a diminuir esse estado, principalmente em pessoas mais ociosas.

É frequente encontrar relatos de maior consumo de alimentos após eventos agradáveis ou desagradáveis, sendo que, a sequência de estímulos e o comportamento do individuo decorrem de história pessoal, construída, muitas vezes, desde tenra idade (Ades \& Kerbauy, 2002). Assim, o ato de comer parece estar relacionado a uma tentativa de preencher vazios existenciais e psicológicos, que também estão relacionados ao cotidiano do obeso.

(Ind.5) - "Sem nada, de repente... dá aquela ansiedade em mim, éuma coisa estranha, aíeu vou pro-curar, àsvezesatéos "bobes" (cabelo) eumudo, praverseeuesqueço da comida, atéfazer algum trabalho mas, quando termino fico sentindo uma falta...".

(Ind.6) - (quando se olha no espelho) "Ave Maria! Me sinto... Ave Maria! Tenho uma vontade de chorar eu me aperreio, ai meu Deus, aípronto, aíse eu ficar mais assim, aí éque eu fico com vontade de comer".

Esses depoimentos confirmam o pressuposto

514 de que o ser humano é o único na natureza a utilizar o ato de se alimentar para outros fins que não o de obter nutrientes necessários para seu desenvolvimento. Mais da metade do que se come, faz-se pelos olhos; em outras palavras, o fato de ter os alimentos por perto, e facilmente disponíveis, contribui para que eles sejam consumidos (Viuniski, 2000; Wansink, 2004).

Em um estudo citado por Canetti, Bachar e Berry (2002), foi investigada a relação entre diferentes emoções e a quantidade de comida ingerida. Os autores concluíram que o elevado consumo de comida ocorria durante o tédio, a depressão e a fadiga, enquanto o baixo consumo ocorria durante o medo, a tensão e a dor. Segundo os autores, a influência das emoções no comportamento de comer é maior em pessoas obesas do que em pessoas obesas, e maior em pessoas que fazem dieta do que naquelas que não a fazem.

Em outro estudo, citado por Canetti, Bachar e Berry (2002) mostrou uma grande tendência ao consumo de comidas saudáveis durante emoções positivas, e uma grande tendência ao consumo de junk foods (comidas de lanchonete) durante emoções negativas.

Esse consumo muito voltado para a oralidade é característico da sociedade capitalista em que se vive, que é extremamente consumista (Stenzel, 2003).

Evidenciou-se, nas entrevistas, que os alimentos preferidos dos indivíduos obesos são massas e doces, tais como pão, pizza, pastel, bolo e chocolate, e que eles tinham fácil disponibilidade desses alimentos no trabalho ou em casa - alimentos mais disponíveis do ponto de vista financeiro, porém, hipercalóricos.

A constatação desse fato ainda pode ser obtida a partir dos dados da Pesquisa de Orçamentos Familiares (POF), realizada pelo Instituto de Geografia e Estatística (IBGE-2004), entre 2002 e 2003, em que o consumo per capita (kg) de alimentos preparados apresentou um aumento de 98,6\% entre 1996 e 2003. São alimentos com alto conteúdo energético (IBGE, 2004) e porções de grande tamanho, cujo consumo vem aumentando continuamente nos últimos anos, principalmente em paises desenvolvidos (Raghubir \& Krishna, 1999; Young \& Nestle, 2002), mas também em países em desenvolvimento, como o Brasil.

Tonial (2001) relata que as mulheres desnutridas e obesas, pobres, percebem sua condição corporal fora 
dos padrões de normalidade, conhecem os princípios básicos de alimentação saudável e demonstram que a pobreza é o impedimento para praticarem uma alimentação saudável, tanto para si quanto para a sua família, evidenciando assim, fato já comprovado na literatura, que uma alimentação saudável é mais cara que uma hipercalórica (Drewnowski \& Specter, 2004).

O fato de entrar em um estado de angústia/ansiedade, não conseguir se controlar e alimentar-se em seguida, pode levar ao sentimento de culpa observável no discurso dos entrevistados. A culpa é a determinação ontológica do existencial da facticidade; nesse sentido, ela é um modo de ser do Dasein (ser-aí) fático e diz respeito ao fato de o homem estar-lançado no mundo e misturado com ele (Ferreira, 2002).

O sentimento de culpa atinge maiores proporções pelo fato de o indivíduo estar obeso, de estar "gordo", como exposto a seguir:

(Ind.3) -"Eu tento me controlar, mas, às vezes eu não consigo, já até joguei comida para eu não comer".

(Ind.3) - "Eu não aguento ficar em casa sem comer... eu gosto de estudar... nas últimas semanas engordei muito, eu não gosto mais nem de pensar... eu não acho justo com meu marido e meus filhos estar com esse peso (chora)...".

(Ind.9) - "... Às vezes eu saio com meu marido, assim na semana, para comerpastel; Tem nada a ver comer pastel! tem nada a ver a pessoa com janta em casa comer pastel comsuco e refrigerante!".

De acordo com a citação de Wajner (2000), há dois tipos de condutas em pacientes obesos: as condutas impulsivas, quando o impulso de comer é irrefreável, mas não há sensação de culpa; e as condutas compulsivas, quando o paciente come, mas existe luta interna e sensação de culpa. Essa culpa surge da perda de controle expressa na ingestão excessiva de alimento e vem muitas vezes acompanhada de sentimentos depressivos.

Segundo Gilman (2004), vive-se um pânico moral sobre a obesidade; as pessoas estão encarando a gordura como uma "maldição da civilização ocidental", e acentuar ainda mais esse sentimento, fazendo-as sentirem-se culpadas por serem gordas, é uma forma inútil de controle de peso (Stearns, 1997).

Grande parte dos entrevistados associou a obesidade a patologias, tais como problemas cardíacos, pro- blemas de pressão, entre outros, demonstrando claramente seu conhecimento sobre o assunto, e, ao contrário do que muitos profissionais pensam, eles sabem o que está acontecendo consigo mesmos. Ocorre que boa parte dos profissionais trabalha sozinha, sem considerar esse conhecimento dos indivíduos, prescrevendo dietas e medicamentos, sem perceber aquilo de que esses pacientes realmente precisam.

Para algumas pessoas, a negação do problema pode ser a única forma encontrada para conseguir conviver com determinada enfermidade; essa negação não significa necessariamente que o indivíduo não saiba que está obeso - e, sim, que não consegue mais aceitar a obesidade, e que precisa de um tempo para tentar encarar o problema novamente. Esse fato foi encontrado no relato de uma paciente;

(Ind.3) - "Eu não penso muito nisso, eu acho até que isso me prejudica, por não me achar obesa".

Essa negação também pode ser identificada no seguinte relato:

(Ind.1) - "Me sentia gordo assim, tinha dúvida se era gordo ou obeso... me sinto obeso, porque fiz agora o IMC...".

Este indivíduo mostra claramente seu conhecimento sobre estar acima do peso, porém só aceitou que estava obeso após se submeter ao cálculo do Índice de Massa Corporal (IMC).

Segundo Almeida et al. (2002), a angústia apresenta um fenômeno correlato que é a queda, na qual o homem se fecha a si mesmo, na medida em que se absorve no mundo e, como consequência, nos outros. Assim, a queda, que é fechar-se em si mesmo, exibe o ser-aí fugindo de si mesmo, o que lhe veda a autenticidade de ser ele mesmo.

Sendo assim, dentre todos os fatores ligados ao excesso de peso e à obesidade, a sociedade, interferindo diretamente na alimentação e na apologia da imagem física perfeita, exerce influência importante, seja na etiologia, seja no tratamento, seja ainda na prevenção (Bacon et al., 2002; Costa, Moura, Cavalcanti, Dias \& Costa, 2003).

Diante dessa realidade, questiona-se: o que a sociedade, especificamente no Brasil, está fazendo para interferir de forma positiva no hábito alimentar dos indivíduos? 
O Brasil já desenvolve ações de promoção à saúde, com o objetivo de prevenir o aumento da prevalência do sobrepeso e da obesidade, desde 1999, quando foi homologada a Política Nacional de Alimentação e Nutrição (PNAN), do Ministério da Saúde. Essa política contém as diretrizes programáticas, através das quais pretende alcançar o objetivo de "promover, proteger e apoiar práticas alimentares e estilos de vida que levem a um nível nutricional e de saúde ideal". Para alcançar esse objetivo, o plano está apoiado em um tripé que inclui legislação, informação e desenvolvimento de recursos humanos (Brasil, 1999). No entanto, após cinco anos de parceria governamental, ainda não se conseguiu visualizar impacto na prevalência dessa patologia, conforme os dados apresentados no Estudo de Caso Brasil 2005 (Brasil, 2005).

No âmbito da legislação, as leis que regulam a rotulagem nutricional dos alimentos, em vigor desde 2002, visam auxiliar o consumidor a fazer escolhas alimentares informadas e mais saudáveis (Agência Nacional de Vigilância Sanitária, 2001).

Ainda no Brasil, durante o V Fórum Social Mundial, foi elaborado um documento sobre a influência da publicidade no consumo alimentar da população brasileira, defendendo a ação imediata do estado na regulamentação da publicidade de alimentos. Essa ação contou também com o apoio da sociedade civil no controle da comercialização de lanches nas cantinas escolares, como já ocorre no estado do Rio de Janeiro, onde a Portaria n 02/2004 disciplina o consumo de alimentos em escolas e apresenta alternativas alimentares substitutas saudáveis (Conselho Federal de Nutricionistas, 2005).

Mudanças ocorridas no processo industrial também são fatores que interferem na saúde dos indivíduos, tais como o crescimento da oferta de refeições rápidas e de alimentos com alta densidade energética, o entretenimento passivo com a televisão, entre outros aspectos. É preciso que as várias instâncias sociais - governo, setor privado, organizações não governamentais, mídia e sociedade civil - em amplo processo de discussão, planejem e implantem medidas para manter a higidez da população, de forma contínua e permanente, considerando que as mudanças decorrentes das novas tecnologias estão geralmente relacionadas ao agravamento e/ou à ocorrência de condições identificadas como novas patologias, como é o caso da obesidade. E isso é mais preocupante porque sua prevalência está aumentando em todo o mundo, atingindo todas as faixas etárias e todas as classes sociais.

A partir dos dados aqui apontados, percebe-se que a redução da prevalência da obesidade está atrelada também ao comportamento da sociedade diante do obeso. Se o obeso deixar de ser visto como alguém "fora dos padrões", com um olhar de pena ou discriminação, sob a taxa de preguiçoso, desleixado ou "baleia" que instala nele um sentimento de culpa e de vergonha, somente assim a sociedade estará contribuindo para sua luta contra aquela patologia.

\section{Considerações Finais}

Os aspectos sociais possuem um papel importante tanto na incidência da obesidade quanto em seu tratamento.

Em um primeiro momento, eles estimulam os indivíduos a hábitos errôneos, como a alimentação hipercalórica de fácil acesso e a falta de estímulo à atividade física diária.

Em um segundo momento, observou-se que os indivíduos participantes desta pesquisa parecem desenvolver uma autoimagem negativa, relacionada à ansiedade e à depressão, entre outros aspectos, que pode levá-los a um sentimento de culpa. Esse sentimento é ainda reforçado pela discriminação de uma sociedade que, ao invés de ajudá-lo a perder peso, parece estimulá-lo a comer mais. Nesse caso, o alimento serve de compensação momentânea para aliviar a ansiedade, entre outros sentimentos negativos.

Diante dessa realidade, a sociedade precisa traçar um novo olhar sobre o indivíduo obeso, procurando ajudá-lo, eliminando o preconceito, a estigmatização e o incentivo a maus hábitos alimentares, assim proporcionando-Ihe o acesso a uma melhor qualidade de vida. Para isso é necessária a realização de novos estudos e a criação de políticas públicas eficazes. O termo obesidade precisa deixar de ser visto de forma discriminatória, uma vez que o obeso, estando "fora dos padrões de beleza", encontra-se cada vez mais "fora da sociedade". 


\section{Referências}

Ades, L., \& Kerbauy, R. R. (2002). Obesidade: realidades e indagações. Psicologia USP, 13 (1), 197-216.

Agência Nacional de Vigilância Sanitária. (2001, 22 de março). Resolução-RDC n 39, de 21 de março de 2001. Tabela de valores de referência para porções de alimentos e bebidas embalados para fins de rotulagem nutricional. Diário Oficial da União.

Almeida, S. S., Nascimento, P. C., \& Bolzan, T. C. (2002). Quan-tidade e qualidade de produtos alimentícios anunciados na televisão brasileira. Revista de Saúde Pública, 36 (3), 353-355.

Bacon, L., Keim, N. L., van Loan, M. D., Derricote, M., Gale, B., Kazaks, A., et al (2002). Evaluating a 'non-diet' wellness intervention for improvement of metabolic fitness, psychological well-being and eating and activity behaviours. International Journal of Obesity Related Metabolic Disorders, 26 (6), 854-865.

Bardin, L. (2004). Análise de conteúdo (3a ed). Lisboa: Edições 70.

Bettarello, S. V. (1998). Perspectivas psicodinâmicas em psiquiatria. São Paulo: Lemos Editorial.

Brasil. Ministério da Saúde. (1999). Plano nacional para promoção da alimentação adequada e do peso saudável. Brasília: MS.

Brasil. Ministério da Saúde. (2005). Estudo de caso Brasil: a interação das ações de alimentação e nutrição nos planos de desenvolvimento nacional para o alcance das metas do milênio no contexto do direito humano à alimentação adequada. Brasília: MS.

Brownell, K. D. (2000). The learn program for weight control: lifestyle, exercise, attitudes, relationships, nutrition. Dallas: American Health.

Canetti, L., Bachar, E., \& Berry, E. (2002). Food and emotion. Behavioural Processes, 60 (2), 157-164.

Cardoso, S. C. M. (2000). Para uma abordagem sociológica dos distúrbios alimentares. In Actas do VI Congresso Portugues de Sociologia. Lisboa, Portugal.

Contaldo, F., \& Pasanisi, F. (2004). Obesity epidemics: secular trend or globalization consequence? Beyond the interaction between genetic and environmental factors. Clinical Nutrition, 23 (3), 289-291.

Conselho Federal de Nutricionistas. (2005). Publicidade de alimentos precisa de regulação. Revista do Conselho Federal de Nutricionistas, 15, 16-17.

Conselho Nacional de Saúde. (1996). Resolução no 196/96. Recuperado em abril 15, 2002, disponível em: <http:// conselho.saude.gov.br/comissao/conep/resolucao.html>.

Costa, R. C., Moura, L. S. A., Cavalcanti, A. P. R., Dias, M. R., \& Costa, M. J. C. (2003). Crenças dos pacientes obesos sobre o comportamento de reduzir o peso através de uma dieta. Resumos de comunicações científicas do XI Encontro de Iniciação Científica da UFPB (p.55). João Pessoa: UFPB.
Derenne, J. L., \& Beresin, E. V. (2006). Body image, media, and eating disorders. Academic Psychiatry, 30 (3), 257-61.

Drewnowski, A., \& Specter, S. E. (2004). Poverty and obesity: the role of energy density and energy costs. American Journal Clinical Nutrition, 79, 6-16.

Faith, M. S., Flint, J., Fairburn, C. G., Godwin, G.M., \& Alison, D. B. (2001). Gender differences in the relationship between personality dimensions and relative body weigth. Obesity Research, 9 (10), 647-650.

Ferreira, A. M. C. (2002). Culpa e angústia em Heidegger. Cogito, 4, 75-79.

Gilman, S. L. (2004). Fat boys: a slim book. Lincoln: University of Nebraska Press.

Hancox, R. J., \& Poulton, R. (2006). Watching television is associated with childhood obesity: but is it clinically important? International Journal of obesity, 30, 171-175.

Instituto Brasileiro de Geografia e Estatística. (2004). Pesquisa de orçamentos familiares 2002-2003: aquisição alimentar domiciliar per capita. Brasília: IBGE.

Lüdke, M., \& André, M. E. D. A. (1986). Pesquisa em educação: abordagens qualitativas. São Paulo: EPU.

Minayo, M. C. S. (1999). O desafio do conhecimento: pesquisa qualitativa em saúde. São Paulo: Hucitec.

Morato, H. T. P. (1999). Aconselhamento psicológico centrado na pessoa: novos desafios. São Paulo: Casa do Psicólogo.

Nogueira-Martins, M. C. F. (2004). Humanização das relações assistenciais: a formação do profissional de saúde. São Paulo: Casa do Psicólogo.

Prentice, A. M., \& Jebb, S. A. (2003). Fast foods, energy density and obesity: a possible mechanistic link. Obesity Review, 4 (4), 187-194.

Puhl, R. M., \& Brownell, K. D. (2003). Psychossocial origins of obesity stigma: toward changing a powerful and pervasive bias. Obesity Review, 4, 213-227.

Raghubir, P., \& Krishna, A. (1999). Vital dimensions in volume perception: can the eye fool the stomach? Journal of Marketing research, 36 (3), 31-326.

Rogers, C. R. (1992). Terapia centrada no cliente. São Paulo: Martins Fontes.

Savage, P. D ., \& Ades, P. A . (2006). The obesity epidemic in the United States: role of cardiac rehabilitation. Coronany Artery Disease, 17 (3), 227-231.

Schwartz, M. B. \& Brownell, K. D. (2004). Obesity and body image. Body Image, 1 (1), 43-56.

Stearns, P. N. (1997). Fat History: bodies and beauty in the Modern West. New York: University Press.

Stenzel, L. M. (2000). A Dialética obesidade/magreza: um estudo em representações sociais com adolescentes. Dissertação de mestrado não-publicada, Programa Pós-Graduação em Psicologia Social e da Personalidade, Pontifícia Universi-dade Católica do Rio Grande do Sul, Porto Alegre.

Stenzel, L. M. (2003). Obesidade: o peso da exclusão (2a ed.). Porto Alegre: EDIPUCRS. 
Tonial, S. R. (2001). Desnutriçãoe obesidade:faces contraditórias na miséria e na abundância. Recife: IMIP.

Turato, E. R. (2003). Tratado da metodologia da pesquisa clínico-qualitativa: construção teórico-epistemológica, discussão comparada e aplicação nas áreas de saúdee humanas. Petrópolis: Vozes.

Viuniski, N. (2000). Prevenindo a obesidade: trabalhando com os fatores de risco. Nutrição em Pauta, 41, 31-34.

Volkow, N. D., Wang, G. J., Fowler, J. S., Logan, J., Jayne, M., Franceschi, D., et al. (2002). "Nonhedonic" food motivation in humans involves dopamine in the dorsal striatum and methylphenidate amplifies this effect. Synapse, 44 (3), 175-180.
Wajner, S. (2000). Aspectos dinâmicos, psicossociais e comportamentais da obesidade. Revista de Psicologia da Ulbra, 12, 91-97.

Wansink, B. (2004). Environmental factors that increase the food intake and consumption volume of unknowing consumers. Annual Review of Nutrition, 24, 455-479.

Young, L. R., \& Nestle, M. (2002). The contribution of expanding portion sizes to the US obesity epidemic. American Journal of Public Health, 92 (2), 246-249.

Recebido em: 11/2/2011

Versão final em: 10/10/2011

Aprovado em: 28/3/2012

518 